\title{
The Effects of Bilirubin on Brain Energy Metabolism during Normoxia and Hypoxia: An in Vitro Study Using ${ }^{31} \mathrm{P}$ Nuclear Magnetic Resonance Spectroscopy
}

\author{
N. K. IVES, D. W. G. COX, R. M. GARDINER, AND H. S. BACHELARD \\ Department of Paediatrics, School of Medicine, University College, The Rayne Institute, [N.K.I., R.M.G.] and \\ Division of Biochemistry, U.M.D.S. (St Thomas' Hospital), [D.W.G.C., H.S.B.], London England
}

\begin{abstract}
Available evidence from in vitro studies suggests that the neurotoxic effects of bilirubin may be exacerbated by, or even require, additional factors such as hypoxia or asphyxia. The aim herein was to use ${ }^{31} P$ nuclear magnetic resonance spectroscopy to study the effects of bilirubin on brain energy metabolism in vitro under conditions of normoxia and hypoxia. ${ }^{31} \mathrm{P}$ nuclear magnetic resonance spectra were acquired from guinea pig cerebral hemisphere slices during superfusion with solutions containing bilirubin and albumin in 5:1 molar ratio. The effects of bilirubin at concentrations between $400 \mathrm{nmol} /$ liter and $120 \mu \mathrm{mol} /$ liter were studied under normoxic conditions. Bilirubin caused no apparent disruption in brain energy metabolism during normoxia. The combined effects of bilirubin (40 $\mu \mathrm{mol} / \mathrm{liter}$ ) and hypoxia were studied. Hypoxia alone led to a steady state reduction in the phosphocreatine to inorganic phosphate peak-height ratio to $0.30(0.27-$ 0.32 ) [mean (range) $n=3$ ]. Bilirubin ( $40 \mu \mathrm{mol} /$ liter) in the presence of hypoxia caused a further reduction in the phosphocreatine to inorganic phosphate ratio to 0.18 (0.17-0.20) [mean (range) $n=3, p<0.01$, analysis of variance] which was rapidly reversed on returning to normoxia. These results demonstrate that bilirubin at the concentration studied requires hypoxia, in addition, to cause a measurable disturbance of brain energy metabolism. The nature of this interaction is unknown, but it may reflect the effect of intracellular acidosis on bilirubin solubility or the oxygen dependence of brain mitochondrial bilirubin oxidase. (Pediatr Res 23: 569-573, 1988)
\end{abstract}

\section{Abbreviations}

${ }^{31} \mathbf{P}$ NMRS, ${ }^{31}$ phosphorus nuclear magnetic resonance spectroscopy

PCr, phosphocreatine

$\mathbf{P i}$, inorganic phosphate

FID, free induction decay

NPT, nucleoside triphosphate

Although the prevention of Rhesus-hemolytic disease has curtailed the incidence of severe jaundice in term newborn infants, the potential neurotoxicity of bilirubin is still a common and important concern, especially in the care of infants born pre-

Received September 11, 1987; accepted January 29, 1988

Correspondence Dr. N. K. Ives, Department of Paediatrics, University of Oxford, John Radcliffe Hospital, Headington, Oxford OX3 9DU, England.

Supported by Birthright, The National Fund for Research into Crippling Diseases, and the Medical Research Council, UK. maturely. It is well recognized that sick, low birth weight infants are particularly susceptible to bilirubin encephalopathy $(1,2)$, but attempts to identify predictive clinical or biochemical risk factors for this group have been notably unsuccessful $(3,4)$. Guidelines for treatment with phototherapy and exchange transfusion remain at best empirical and at worst arbitrary (5). These clinical uncertainties reflect in part our lack of understanding of how bilirubin enters the brain and exerts its neurotoxic effects.

Previous work in vitro has suggested that bilirubin disrupts brain mitochondrial function and uncouples oxidative phosphorylation $(6,7)$. However, animal studies in vivo have failed to consistently establish a primary effect of bilirubin on brain energy metabolism. ATP depletion and impaired respiration have been reported in the cerebella of kernicteric Gunn rats (8), but mitochondria isolated from whole brain and cerebella of newborn guinea pigs made kernicteric with infusions of bilirubin were not uncoupled (9). Another study failed to establish any difference in respiratory control indices of whole brain mitochondria from neonatal kernicteric Gunn rats and their nonjaundiced heterozygous littermates (10). Similarly, no significant change in brain energy metabolism could be detected using in vivo ${ }^{31} \mathrm{P}$ NMRS in adult Gunn rats when brain bilirubin concentration had been raised to levels found in symptomatic neonatal animals (11).

Uncertainty also surrounds the interrelationship between bilirubin neurotoxicity and other potential causes of brain cell damage. Both clinical experience and animal work in vivo suggest that bilirubin encephalopathy is exacerbated by, or may even require, additional factors such as hypoxia (12), asphyxia (13), or hypercapnia (14). The extent to which these factors may act by alteration of blood-brain barrier permeability $(15,16)$ and cerebral blood flow (17), or by increasing the vulnerability of neurones to bilirubin uptake and toxicity remains unclear.

The aim of these experiments was to study the effects of bilirubin on brain energy metabolism, under conditions of normoxia and hypoxia, at bilirubin concentrations comparable to those found in the brains of experimental animals with bilirubin encephalopathy. The method chosen for performing ${ }^{31} \mathrm{P}$ NMR studies on cerebral tissues superfused in vitro (18) has the advantage of enabling precise manipulation of the immediate environment of the tissue independent of the influence of changes in the cerebral circulation or blood-brain barrier.

\section{METHODS}

Tissue preparation. The preparation was carried out as previously described (19). The brains were rapidly removed from stunned, decapitated adult male Dunkin-Hartley guinea pigs (300-350 g body weight). The subcortical tissues were excised and each cerebral hemisphere prepared using a Mcllwain chop- 
per to give coronal slices of $350 \mu \mathrm{m}$ thickness (20). The tissue slices were immediately transferred to a test tube containing gassed incubation medium, briefly dispersed with a Vortex mixer and decanted into a conical flask containing medium maintained at $37^{\circ} \mathrm{C}$ and constantly gassed with $\mathrm{O}_{2} / \mathrm{CO}_{2}(19: 1)$. The slices were rinsed five times with fresh gassed medium before being transferred to a standard $25-\mathrm{mm}$ diameter NMR tube fitted with a polytetrafluoroethylene insert carrying perfusion tubing and the shaft of a motor-driven glass stirrer. The cerebral cortices from four guinea pigs were pooled to provide 4-5 $\mathrm{g}$ of tissue for each experiment. The incubation medium contained $\mathrm{NaCl}(124$ $\mathrm{mM}), \mathrm{KCl}(5 \mathrm{mM}), \mathrm{KH}_{2} \mathrm{PO}_{4}(1.2 \mathrm{mM}), \mathrm{MgSO}_{4}(1.2 \mathrm{mM}), \mathrm{CaCl}_{2}$ (1.2 $\mathrm{mM}), \mathrm{NaHCO}_{3}(26 \mathrm{mM})$, and glucose $(10 \mathrm{mM})$. Gassing for tissue preparation and control conditions was with $\mathrm{O}_{2} / \mathrm{CO}_{2}(19: 1)$ (19). Conditions of hypoxia were achieved by gassing with air/ $\mathrm{CO}_{2}$ (19:1). The tissues within the NMR tube were superfused with medium at rates of $25-30 \mathrm{ml} / \mathrm{min}$. The motor driven paddle stirrer was adjusted to ensure continuous gentle agitation of the tissues throughout the experiment.

Bilirubin. A solution of bilirubin $(6 \mathrm{mM})$ and albumin $(1.2$ $\mathrm{mM}$ ) was prepared under conditions of subdued light immediately before use. Crystalline bilirubin, $35 \mathrm{mg}$ (Sigma Chemical Co., St. Louis, MO) was dissolved in $930 \mu 1,0.5 \mathrm{M} \mathrm{NaOH}$, and made up to $3650 \mu \mathrm{l}$ with distilled $\mathrm{H}_{2} \mathrm{O}$. Human serum albumin (Kabi Scientific Instrument Corp., El Cajon, CA), $6 \mathrm{ml}$ of a 2 $\mathrm{mM}$ solution, were added and the $\mathrm{pH}$ adjusted to 8.5 with $1 \mathrm{M}$ $\mathrm{HCl}$. An aliquot of this solution was added to the reservoir and circulating superfusate volume of 1.5 liter to give a concentration of bilirubin bathing the brain slices ranging from $400 \mathrm{nmol} / \mathrm{liter}$ to $120 \mu \mathrm{mol} /$ liter. A 5:1 molar excess of bilirubin to albumin was used throughout. The reservoir and superfusion tubing were shielded from light. The $\mathrm{pH}$ of the incubation medium was within the physiological range, and remained so on addition of the bilirubin solution.

${ }^{31} P$ NMRS. ${ }^{31} \mathrm{P}$ NMR spectra were acquired using a Bruker WM 200 wide-bore spectrometer, operating at a frequency of 81 $\mathrm{MHz}$ for phosphorus, with a deuterium lock. Magnet shimming was accomplished by using the FID from the protons in the water of the circulating perfusate. A line width of $5-10 \mathrm{~Hz}$ was normally achieved. Spectra were sequentially accumulated in blocks of 128 FID using $40^{\circ}$ pulses repeated every $8 \mathrm{~s}$. The spectral width was $5.55 \mathrm{KHz}$. In experiments where the composition or level of oxygenation of the superfusing medium were varied, the medium was changed without disturbing the tissue or probe, with continuous recording of spectra. Only steady state spectra were used in analyzing the data. The signal intensity (height) of each peak was measured and calculated as a ratio relative to the Pi peak for that spectrum. The use of peak height as opposed to triangulation was justified because there was no significant change in peak width throughout individual experiments. A considerable proportion of the Pi peak is attributable to $\mathrm{Pi}$ in the superfusion medium and remained essentially constant during a given experiment. Variation in the absolute height of the Pi peak and initial PCr content of the tissues between experiments made it necessary to express the results as a percentage of control values when grouping data.

Experimental design. Control spectra were accumulated during perfusion with standard incubation medium gassed to provide normal tissue oxygenation with $\mathrm{O}_{2} / \mathrm{CO}_{2}$ (19:1). The effects of changing the level of tissue oxygenation by gassing with air/ $\mathrm{CO}_{2}$ (19:1) (hypoxia) or of adding bilirubin to the perfusate were examined individually and in combination.

These factors were studied using three series of experiments in which sequential changes were made to the perfusate. In the first series control observations were followed by superfusion with a bilirubin-containing medium without altering tissue oxygenation. The effects of incremental changes in bilirubin concentration over the ranges $400 \mathrm{nmol} / \mathrm{liter}-4.8 \mu \mathrm{mol} / \mathrm{liter}, 4.2-16.8$ $\mu \mathrm{mol} / \mathrm{liter}$, and $20-120 \mu \mathrm{mol} / \mathrm{liter}$ were studied in three successive experiments. The tissues were exposed to each bilirubin concentration studied for a period of $34 \mathrm{~min}$. Three experiments were performed in which the tissues were exposed to bilirubin (40 $\mu \mathrm{mol} / \mathrm{liter}$ with albumin $8 \mu \mathrm{mol} / \mathrm{liter}$ ) for $68 \mathrm{~min}$. In the second series control observations were followed by a period of tissue hypoxia. With hypoxia maintained the perfusate was then changed to one containing bilirubin at a concentration of 40 $\mu \mathrm{mol} / \mathrm{liter}$ (bilirubin/albumin molar ratio 5:1). The effect of recovery after exposure of the tissue to the combination of bilirubin and hypoxia was studied by reversing the experimental sequence with hypoxia alone and then control conditions. In a third series of experiments bilirubin was omitted and the effect of adding albumin alone to the perfusate was examined under normoxic and hypoxic conditions. Spectra (128 FID) were accumulated during the transition period from one experimental condition to another and indicated that a steady state was achieved within the time period this occupied (approximately 17 $\mathrm{min}$ ). The results of between two and five sequential steady-state spectra (128 FID) were combined for each experimental state and the duration of an individual study was up to $5 \mathrm{~h}$.

Brain slice bilirubin concentration. At the end of each experiment the cerebral slices were retrieved by filtration and washed three times with fresh incubation medium before storage in the dark at $-40^{\circ} \mathrm{C}$. Brain tissue bilirubin content was later estimated after extraction from homogenates with chloroform as described by Sawasaki et al. (21).

Statistics. Statistical significance was determined using analysis of variance and Student's $t$ test.

\section{RESULTS}

A representative ${ }^{31} \mathrm{P}$ NMR spectrum of guinea pig cerebral slices under control conditions $\left(\mathrm{O}_{2} / \mathrm{CO}_{2}, 19: 1\right)$ is shown in Figure 1. The resonances are superimposed on an underlying broad signal attributable to brain phospholipids, and a considerable

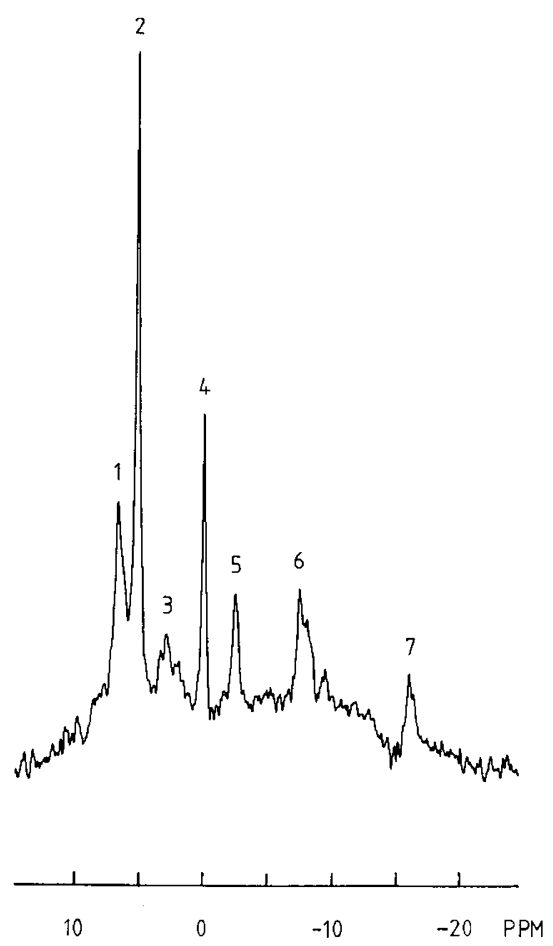

Fig. $1 .{ }^{31} \mathrm{P}$ NMR spectrum of guinea pig cerebral slices acquired under control conditions $\left(\mathrm{O}_{2} / \mathrm{CO}_{2}, 19: 1\right)$. The spectrum was derived from 256 FID collected at 8-s intervals. The $\mathrm{x}$-axis is chemical shift (ppm) and the $\mathrm{y}$-axis signal intensity (AU). Peak assignments: 1 , phosphomonoesters; 2, $\mathrm{Pi} ; 3$, phosphodiesters; 4, $\mathrm{PCr} ; 5,6,7, \gamma, \alpha$, and $\beta$ nucleoside triphosphate peaks. 
proportion (65\%) of the Pi peak arises from the phosphate in the superfusing medium (19). Peak assignments are given in the legend of Figure 1.

Exposure of the tissue to a concentration of bilirubin of up to $120 \mu \mathrm{mol} /$ liter (bilirubin/albumin molar ratio 5:1) had no significant effect on the ${ }^{31} \mathrm{P}$ NMR spectrum if oxygenation was maintained by gassing the medium with $\mathrm{O}_{2} / \mathrm{CO}_{2} 19: 1$. The results are presented as the $\mathrm{PCr} / \mathrm{Pi}$ and NTP/Pi ratios for each of the bilirubin concentrations studied (Fig. 2 ). The " $\beta$-NTP" peak is singled out because unlike the $\alpha$ and $\gamma$ peaks it solely reflects the resonance of the phosphate of a nucleoside triphosphate, largely ATP (22).

A representative sequence of spectra obtained during the course of an experiment investigating the combined effect of bilirubin and hypoxia is shown in Figure 3. The results from three such studies are summarized in Figure 4. Statistical significance was determined by analysis of variance.

Hypoxia alone (air/ $\mathrm{CO}_{2}$ 19:1) led to a steady state reduction in the $\mathrm{PCr} / \mathrm{Pi}$ peak-height ratio to $0.30(0.27-0.32)$ [mean (range), $n=3, p<0.001$, calc. $\mathrm{F}=68.28$, on $5,6 d f$. The addition of bilirubin at a concentration of $40 \mu \mathrm{mol} /$ liter (bilirubin/albumin molar ratio 5:1) caused a further significant reduction in the $\mathrm{PCr} / \mathrm{Pi}$ ratio to $0.18(0.17-0.20)$ [mean (range) $n=$ $3, p<0.01$, calc. $\mathrm{F}=27.84$, on $1,6 d f$. These changes could be reversed on re-perfusing with control incubation medium, but did not return to initial control values on restoring normoxia (Fig. 4). The final control value of $0.47(0.42-0.50)$ was significantly lower than the initial control value of $0.63(0.50-0.77)$ [mean (range), $n=3$, normoxia $p<0.001$, calc. $\mathrm{F}=23.62$, on $5,6 d f$. No significant changes occurred in the phosphomonoester or nucleoside triphosphate peaks.

Three control experiments adopting the same protocol but substituting albumin ( $8 \mu \mathrm{mol} / \mathrm{liter})$ for the bilirubin/albumin mixture showed no detectable effect of albumin on the brain tissue ${ }^{31} \mathrm{P}$ NMR spectrum under conditions of hypoxia (Fig. 5).

The results of all experiments involving a transition from normoxic control conditions to hypoxia alone are shown in Table 1 . The reduction in $\mathrm{PCr} / \mathrm{Pi}$ peak-height ratio from $0.54 \pm$ 0.10 to $0.26 \pm 0.06$ (mean $\pm \mathrm{SD}, n=9$ ) is highly significant ( $p$ $<0.001$, Student's $t$ test), and is in keeping with previously reported observations (19).

Values for brain slice bilirubin concentration determined at the end of each series of experiments are shown in Table 2. There was no significant difference between the bilirubin content of tissues superfused with medium containing bilirubin at a con-

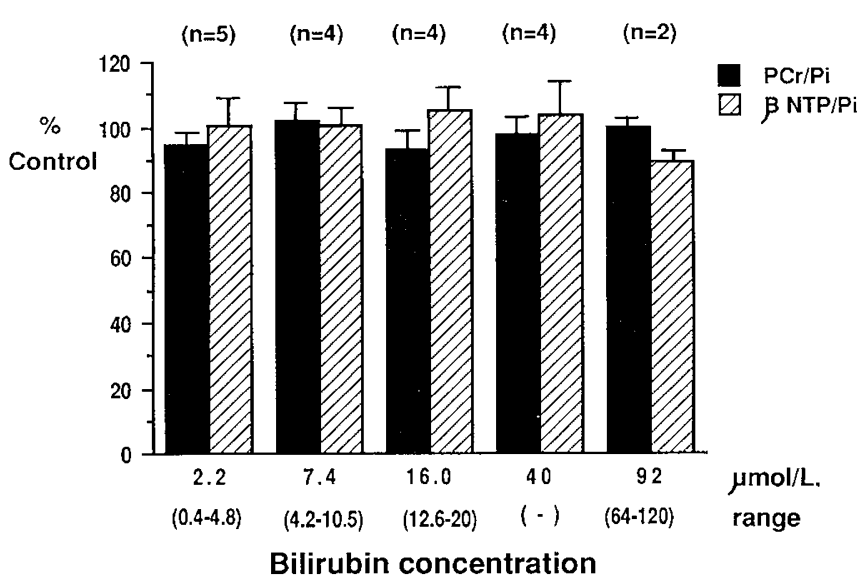

Fig. 2. The effect of bilirubin on the brain ${ }^{31} \mathrm{P}$ NMR spectrum during normoxia. Results are expressed as the mean peak height ratios (\% control) for $\mathrm{PCr} / \mathrm{Pi}$ and NTP/Pi (error bars $=1 \mathrm{SD}$ ). They are grouped as the mean bilirubin concentration of the ranges studied ( $n=$ number of observations). Tissue exposure time was $34 \mathrm{~min}$ for single observations with the exception of three of the studies at $40 \mu \mathrm{mol} /$ liter which were of 68-min duration. (Bilirubin/albumin molar ratio 5:1 throughout.)

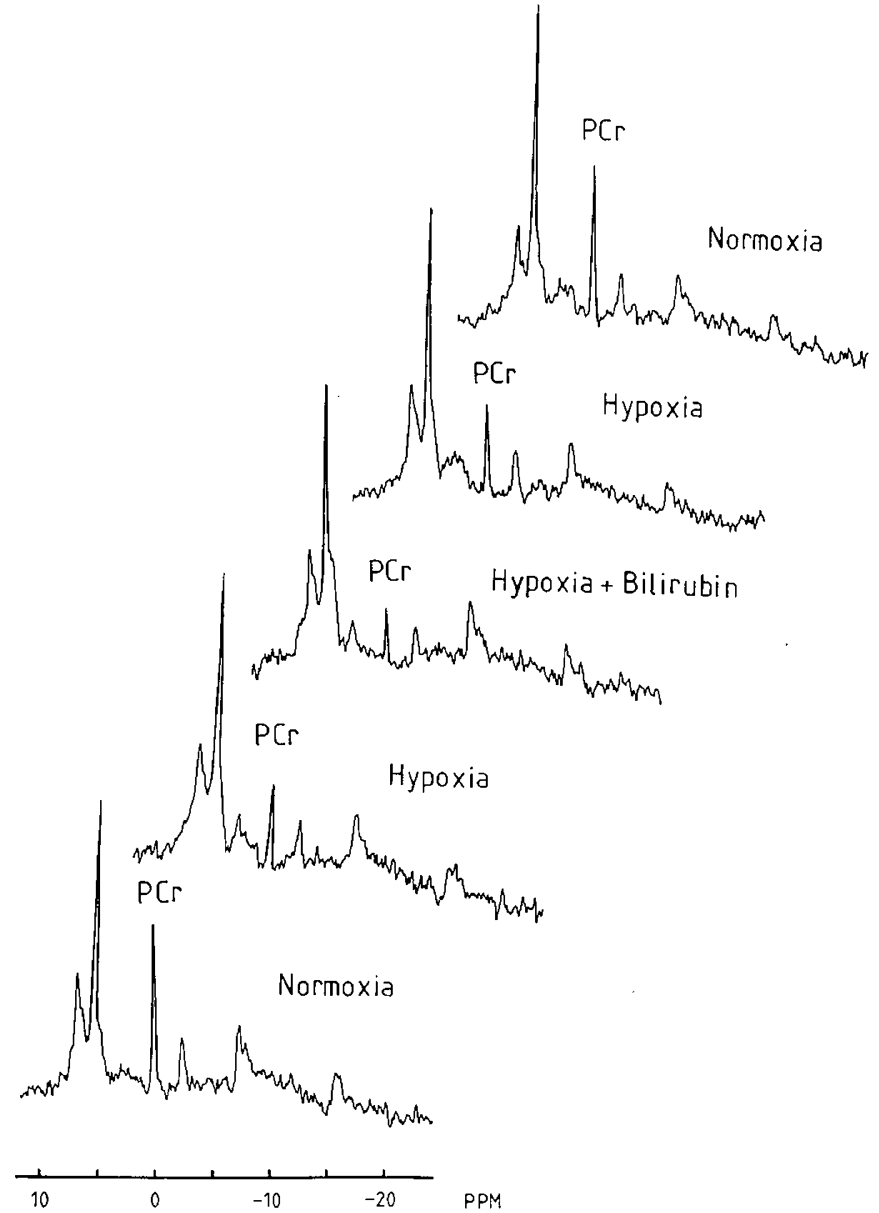

Fig. 3. A representative sequence of spectra collected over a $5-\mathrm{h}$ experimental period. Alterations in the superfusate were as labeled with progression from bottom left to top right. Bilirubin at a concentration of $40 \mu \mathrm{mol} /$ liter (bilirubin/albumin molar ratio $5: 1$ ) in combination with hypoxia was associated with a reversible fall in $\mathrm{PCr}$ below the steady state reduction observed during hypoxia above.

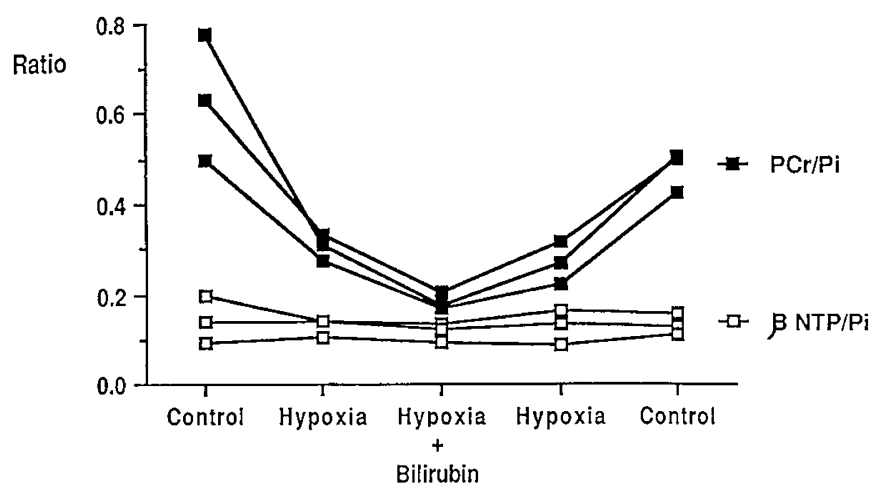

Experimental state

Fig. 4. The combined effects of hypoxia and bilirubin ( $40 \mu \mathrm{mol} / \mathrm{liter})$ on the ${ }^{31} \mathrm{P}$ NMR spectrum. Individual points represent the average $\mathrm{PCr}$ / $\mathrm{Pi}$ and $\beta$-NTP/Pi ratios of two observations for the three experiments at each of the experimental states.

centration of $40 \mu \mathrm{mol} /$ liter under normoxic or hypoxic conditions.

\section{DISCUSSION}

Although yellow staining of the brain in jaundiced newborn infants was recognized over a century ago (23) there was some 
delay before the recognition that bilirubin is the neurotoxic agent responsible for the severe neurological damage associated with icterus gravis in the newborn (24). The mechanism of this neurotoxicity, however, remains uncertain. Observations in vitro using chopped rat brain or isolated liver mitochondria support the suggestion that the primary toxic effect of bilirubin is on brain energy metabolism $(6,7)$. However, the concentration of bilirubin used in such studies greatly exceeded that found in the brain of animals with symptoms of bilirubin encephalopathy $(21,25)$. The advent of ${ }^{31} \mathrm{P}$ NMRS provides the opportunity for a reappraisal of this question.

Certain aspects of the methodology used in these experiments require consideration when interpreting the observations made. The spectrum obtained from brain slices using this technique is reproducible (19) and comparable to that obtained from the intact brain in vivo $(26,27)$. The stability of the "energy state" of brain slices prepared and maintained in this manner, and its sensitivity to metabolic perturbations has been established (19). ${ }^{31} \mathrm{P}$ NMRS has the advantage of allowing sequential observations, but has the limitation of providing measurements of relative changes only in "steady state" levels of individual metabolites. The inclusion of $\mathrm{Pi}$ in the superfusate and the use of interpulse intervals necessarily too short to allow full relaxation preclude, respectively, the quantification of intracellular $\mathrm{pH}$ and of absolute metabolite levels. Observations were made on cerebral hemisphere slices from adult animals and therefore do not take into account any regional or age-dependent variation in neuronal vulnerability to bilirubin.

The cerebral hemispheres were studied instead of the anatomical regions most susceptible to bilirubin staining for several reasons. In practical terms the number of animals required to provide sufficient subcortical tissue would have been unacceptable. Also, correlation was being sought with previous work in which the effects of hypoxia alone had been documented on cerebral hemisphere tissue (19), and with parallel in vivo ${ }^{31} \mathrm{P}$ NMR studies which are necessarily confined to the hemispheres. The aim of this study was to address the specific question of whether bilirubin by itself or in combination with hypoxia dis-

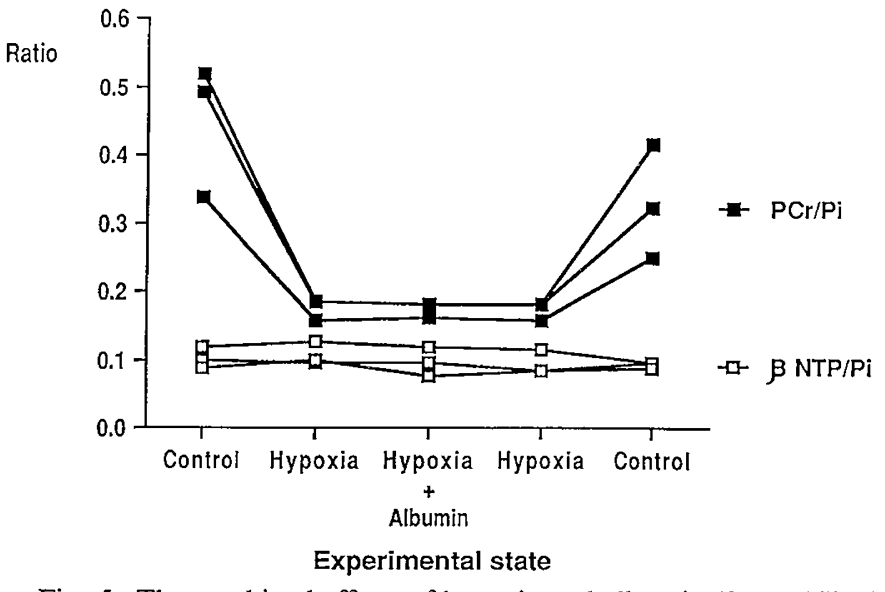

Fig. 5. The combined effects of hypoxia and albumin ( $8 \mu \mathrm{mol} /$ liter $)$ on the ${ }^{31} \mathrm{P}$ NMR. For explanation see legend Figure 4. rupts neuronal energy metabolism. The separate question, of why particular regions of the brain are more vulnerable to bilirubin neurotoxicity, is not approachable by this method.

Superfusion of brain slices with medium containing bilirubin at a concentration up to $120 \mu \mathrm{mol} /$ liter in a 5:1 molar ratio with albumin for periods of between 34-68 min was not associated with any change in the ${ }^{31} \mathrm{P}$ NMR spectrum provided the normal level of oxygenation was maintained. The concentration of bilirubin in medium bathing the tissue was probably less than anticipated due to pigment deposition on tubing and glass. Direct estimation of tissue bilirubin concentrations coincidental with spectral acquisition was not technically feasible in view of the sequential experimental design. Thus values quoted for brain tissue bilirubin concentration (Table 2) apply to assays made after the last experimental state that the slices were exposed to. The values obtained are considered to be an overestimate of bilirubin content, because washing with fresh incubation medium is unlikely to have removed precipitates of bilirubin from the surface of slices. The true intracellular bilirubin concentration cannot be estimated, but would be expected to be within the range observed in symptomatic Gunn rats (25).

These observations suggest that mature cerebral hemisphere tissue can tolerate exposure to bilirubin at a concentration observed in the brain of symptomatic Gunn rats for a period of up to $2 \mathrm{~h}$ without disruption of "energy status." This is in keeping with the failure to demonstrate changes in brain energy metabolism using in vivo ${ }^{31} \mathrm{P}$ NMRS in adult Gunn rats when brain bilirubin concentration had been raised to levels found in symptomatic neonatal animals (11). In contrast, exposure of tissue to the same concentration of bilirubin under conditions of reduced oxygen tension was associated with a significant further reduction in phosphocreatine beyond that occurring in the presence of hypoxia alone. The decrease in phosphocreatine may result from a shift in the creatine kinase equilibrium, due either to a fall in intracellular pH or a failure of the normal balance between ATP generation and consumption. In air/CO $(19: 1)$ the tissue $\mathrm{PO}_{2}$ at the center of the brain slices was sufficiently low to cause oxygen deprivation as evidenced by the spectral changes.

The mechanism of the apparent oxygen dependence of the effect of bilirubin on the ${ }^{31} \mathrm{P}$ NMR spectrum is a matter for speculation. It is possible that a fall in brain pHi under these conditions causes precipitation of bilirubin acid on intracellular organelles including mitochondria. Alternatively, metabolism of bilirubin by brain mitochondrial bilirubin oxidase at reduced oxygen tensions may be insufficient and allow the pigment to accumulate to toxic levels. Such a mechanism has been proposed by Brodersen (28) as a possible etiological factor for bilirubin encephalopathy in the sick newborn infant. In any event, the observations suggest that the interaction of hyperbilirubinemia and hypoxia observed in vivo is not solely accounted for by the effects of hypoxia on the blood-brain barrier or cerebral circulation. Furthermore, the reduction in brain phosphocreatine observed during exposure of hypoxic cerebral tissue slices to bilirubin for a period of up to $1 \mathrm{~h}$ was found to be rapidly reversible on return to the standard superfusate with hypoxia maintained. This may reflect the importance of the duration of tissue insult to the development of permanent brain energy impairment, and as such can be considered analogous to the reversibility of acute changes in the auditory brainstem evoked response after thera-

Table 1. Changes in ${ }^{31} P$ NMR spectrum with hypoxia expressed as peak height ratios (mean $\left.\pm S D\right)^{*}$

\begin{tabular}{|c|c|c|c|c|c|c|}
\hline \multirow{2}{*}{$\begin{array}{l}\text { Experimental } \\
\text { state }\end{array}$} & \multirow{2}{*}{$\begin{array}{c}\text { Duration of } \\
\text { exposure (min) }\end{array}$} & \multirow[b]{2}{*}{ PME/Pi } & \multirow[b]{2}{*}{$\mathrm{PCr} / \mathrm{Pi}$} & \multicolumn{3}{|c|}{ NTP/Pi } \\
\hline & & & & $\gamma$ & $\alpha$ & $\beta$ \\
\hline Control $(n=9)$ & $57 \pm 15$ & $0.28 \pm 0.05$ & $0.54 \pm 0.10$ & $0.16 \pm 0.04$ & $0.17 \pm 0.05$ & $0.13 \pm 0.04$ \\
\hline Hypoxia $(n=9)$ & $42 \pm 12$ & $\begin{array}{c}0.28 \pm 0.05 \\
\mathrm{NS}\end{array}$ & $\begin{array}{c}0.26 \pm 0.06 \\
<0.001\end{array}$ & $\begin{array}{c}0.15 \pm 0.03 \\
\text { NS }\end{array}$ & $\begin{array}{c}0.15 \pm 0.03 \\
\mathrm{NS}\end{array}$ & $\begin{array}{c}0.14 \pm 0.02 \\
\text { NS }\end{array}$ \\
\hline
\end{tabular}

* Statistical significance calculated by Student's $t$ test. 
Table 2. Brain slice bilirubin concentration

\begin{tabular}{|c|c|c|c|}
\hline \multirow{2}{*}{\multicolumn{2}{|c|}{$\begin{array}{l}\text { Superfusate composition } \\
\qquad(\mu \mathrm{mol} / \mathrm{liter})\end{array}$}} & \multicolumn{2}{|c|}{$\begin{array}{l}\text { Brain slice bilirubin } \\
\text { concentration }\end{array}$} \\
\hline & & $(\mathrm{nmol} / \mathrm{g})$ & (range) \\
\hline \multicolumn{4}{|l|}{ Normoxia } \\
\hline Bilirubin & $0.4-4.8$ & $29^{*}$ & \\
\hline Bilirubin & $4.2-16.8$ & $126^{*}$ & \\
\hline Bilirubin & $20-120$ & $400^{*}$ & \\
\hline Bilirubin & 40 & 140 & $(64-197) \dagger$ \\
\hline \multicolumn{4}{|l|}{ Hypoxia } \\
\hline Bilirubin & 40 & 153 & $(73-201) \dagger$ \\
\hline Albumin & 8 & 4 & $(1-7) \dagger$ \\
\hline
\end{tabular}

* Single estimations after incremental changes in bilirubin concentration over the range shown.

$\dagger$ Mean estimations (range) $n=3$.

peutic intervention with exchange blood transfusion (29). The failure to achieve initial baseline values on returning the tissues to control conditions in both the bilirubin and albumin experiments may reflect permanent disruption in brain energy status after prolonged hypoxia or a general deterioration in tissue viability with time.

Acknowledgments. The authors acknowledge Mr. C. B. Pierce, University Data Centre, Oxford University for advice given on statistical methods, Miss Minakshi Joshi for providing excellent technical assistance, and Miss Gail Davies for preparing the manuscript.

\section{REFERENCES}

1. Ackerman BD, Dyer GY, Legdorf MM 1970 Hyperbilirubinaemia and kernicterus in small premature infants. Pediatrics 45:918-925

2. de Vries LS, Lary S, Dubowitz LMS 1985 Relationship of serum bilirubin levels to ototoxicity and deafness in high-risk low-birth weight infants. Pediatrics 76:351-354

3. Ritter DA, Kenny JD, Norton HJ, Rudolph AJ 1982 A prospective study of free bilirubin and other risk factors in the development of kernicterus in premature infants. Pediatrics 69:260-266

4. Turkel SB, Miller CA, Guttenberg ME, Moynes DR, Hodgman JE 1982 A clinical pathologic reappraisal of kernicterus. Pediatrics 69:267-272

5. Lucey JF 1982 Bilirubin and brain damage - a real mess. Pediatrics 69:381383

6. Day RL 1954 Inhibition of brain respiration in vitro by bilirubin: reversal of inhibition by various means. Am J Dis Child 88:261-264

7. Zetterstrom R, Ernster L 1956 Bilirubin, an uncoupler of oxidative phosphorylation in isolated mitochondria Nature 178:1335-1337
8. Schenker S, McCandless DW, Zollman PE 1966 Studies of cellular toxicity of unconjugated bilirubin in kernicteric brain. $\mathbf{J}$ Clin Invest 45:1213-1220

9. Diamond I, Schmid R 1966 Oxidative phosphorylation in experimental bilirubin encephalopathy. Science 155:1288-1289

10. Menken M, Weinbach EC 1967 Oxidative phosphorylation and respiratory control of brain mitochondria isolated from kernicteric rats. J Neurochem 14:189-193

11. Ives NK, Cady EB, Joshi M, Gardiner RM, Reynolds EOR 1986 Bilirubin neurotoxicity: an in vivo ${ }^{31} \mathrm{P}$ MR spectroscopy study in the Gunn rat. In Proceeding of the 5th Annual Meeting of the Society of Magnetic Resonance in Medicine 689 (abstr). Society of Magnetic Resonance in Medicine, Berkeley

12. Chen HC, Lien I-N, Lu T-C 1965 Kernicterus in newborn rabbits. Am J Pathol $46: 331-336$

13. Lucey JF, Hibbard E, Behrman RE, Esquiver de Gallardo FO, Windle WF 1964 Kernicterus in asphyxiated newborn rhesus monkeys. Exp Neurol 9:43-58

14. Lending M, Slobody LB, Mestern J 1966 The relationship of hypercapnia to the production of kernicterus. Dev Med Child Neurol 9:145-151

15. Bratlid D, Cashore WJ, Oh W 1984 Effect of acidosis on bilirubin deposition in rat brain. Pediatrics 73:431-434

16. Wennberg RP, Hance AJ 1986 Experimental bilirubin encephalopathy: importance of total bilirubin, protein binding, and blood-brain barrier. Pediatr Res 20:789-792

17. Burgess GH, Oh W, Bratlid D, Brubakk A-M, Cashore WJ, Stonestreet BS 1985 The effects of brain blood flow on brain bilirubin deposition in newborn piglets. Pediatr Res 19:691-696

18. Bachelard HS, Cox DWG, Feeney J, Morris PG $1985{ }^{31} \mathrm{P}$ nuclear magnetic resonance studies on superfused cerebral tissues. Biochem Soc Trans 13:835839

19. Cox DWG, Morris PG, Feeney J, Bachelard HS $1983{ }^{31}$ P-n.m.r. studies on cerebral energy metabolism under conditions of hypoglycaemia and hypoxia in vitro. Biochem J 212:365-370

20. McIlwain H, Bachelard HS 1985 Biochemistry and the Central Nervous System, 5th ed. Churchill Livingstone, Edinburgh

21. Sawasaki Y, Yamada Y, Makajima H 1976 Developmental features of cerebellar hypoplasia and brain bilirubin levels in a mutant rat with hereditary hyperbilirubinaemia. J Neurochem 27:577-583

22. Gadian DG 1982 NMR and its Application to Living Systems. Clarendon Press, Oxford

23. Orth J 1875 Veber das Vorkommen von Bilurubin-krystallen bei neugeborneni Kindern. Virchows Arch [A] 63:447

24. Mollison PL, Cutbush M 1949 Haemolytic disease of the newborn: criteria of severity. Br Med J 1:123-130

25. Diamond I, Schmid R 1966 Experimental bilirubin encephalopathy. The mode of entry of bilirubin ${ }^{14} \mathrm{C}$ into the central nervous system. J Clin Invest 45:678-689

26. Chance B, Nakase Y, Bond M, Leigh JS, McDonald G 1978 Detection of ${ }^{31} \mathrm{P}$ nuclear magnetic resonance signals in brain by in vivo and freeze-trapped assays. Proc Natl Acad Sci USA 75:4915-4929

27. Ackerman JJH, Grove TH, Wong GG, Gadian DG, Radda GK 1980 Mapping of metabolites in whole animals by ${ }^{31} \mathrm{P}$ NMR using surface coils. Nature 283:167-170

28. Brodersen R 1980 Bilirubin transport in the newborn infant, reviewed with relation to kernicterus. J Pediatr 96:349-356

29. Wennberg RP, Ahlfors CE, Bickers R, McMurtry MA, Shetter JL 1982 Abnormal auditory brainstem response in a newborn infant with hyperbilirubinaemia: improvement with exchange transfusion. J Pediatr 100:624626 